\title{
To Explore the Origin and Traces: Research on the Evolution of the Modeling of Traditional Ceramic Prunus Vase*
}

\author{
Weifang Ke \\ College of Ceramic Art \\ Jingdezhen Ceramic institute \\ Jingdezhen, China 333403
}

\author{
Xiaosong Zou \\ College of Ceramic Art \\ Jingdezhen Ceramic institute \\ Jingdezhen, China 333403
}

\begin{abstract}
The traditional prunus vase has the characteristics of elegance and exquisiteness. The size and proportion of its modeling constantly have changes in different times. The comparative method and the literature method are used in this paper. From the perspective of ergonomics and function transformation, this paper aims at exploring the traditional prunus vase modeling and the reasons for the evolution of function.
\end{abstract}

Keywords—prunus vase; modeling; evolution; reason

\section{INTRODUCTION}

The prunus vase produced in different regions of different historical periods has different shapes and styles. And they jointly interpret the variety of Chinese traditional prunus vase. Since its birth, the prunus vase, like many other arts and crafts, has gone through the process of changing from daily use to funeral services and furnishings. And it has completed the functional transition from practicality to ceremonial and the aesthetics. The author explores the reason why the shape and function of traditional Chinese prunus vase has evolved.

\section{THE INHERENT NEEDS OF FUNCTIONAL EVOLUTION}

According to the American psychologist Maslow's hierarchy of needs theory, first of all, human needs are multilayered. That is to say, people have different needs such as physical, security, love, respect and self-actualization [1]. Secondly, lower-level needs should be prior to the high-level needs. The more advanced the need is, the less urgent it is to maintain the purest existence. However, the more advanced needs of satisfaction can lead to more desirable subjective effect. And it would produce a greater sense of well-being and inner abundance of life [2]. The multi levels and complexity of human needs determine the richness of pursuing daily necessities. Corresponding to the needs of people, in order to meet the most basic and lowest level of human needs, it achieves the most basic practical functions

*Fund Project: creative talents training of famille-rose porcelain of National Arts Foundation in 2017, project number: 2017-A-04-(125)-0639. Fund Project: cultural and arts science planning project in Jiangxi Province in 2016, project number: YG2016055I of the product. It should meet the needs of low-level physical and living things. And it gradually needs to consider the social and spiritual needs of products. With the production and development of society, the functional needs of prunus vase are changed into the aesthetic needs of society. Therefore, the function evolution of prunus vase is essentially the continuous transformation of human needs. Also, it is the constant pursuit of high-level needs.

As a storage device, the practical function of prunus vase is the dominant factor that restricts instrumental design. In the production of prunus vase, ancient craftsmen mainly consider the following two aspects to achieve the practical and artistic harmony of prunus vase modeling. First, the small mouth, short and narrow neck makes it suitable for stamped seal. It would avoid the volatility of alcohol. And we can move it easily without sprinkling out of the bottle. At the same time, when we pour the wine, the clear transition among mouth, neck, shoulder, abdomen and other modeling features would be conducive to control the flow and velocity of wine. Second, the slender body can increase its capacity as much as possible. It would achieve large and economical requirements. The shape of prunus vase is basically determined in the Song dynasty. It should adhere to the principle of convenience and economy in the future development process and constantly improve its functions. Due to the passage of time, changes in the times and social development, it leads to the gradual changes in people's lifestyle and living habits. And the functional requirements of the prunus vase gradually have been changed. The capacity, size and modeling details of prunus vase have gradually been changed. For example, according to the author's previous study, there is an increasing trend in the diameter of prunus vase. The prunus vase gradually separated from the bottom supporter since the Song dynasty. And the bottom supporter demanded that it had the function of independent and stable placement. In addition, the improvement of process materials and the application of advanced technologies provide means, methods and the possibility of evolution to the realization of ceramic prunus vase.

The unique charm of the prunus vase is that it meets the requirements of practical functions. The prunus vase shape 
has formal beauty and artistic beauty on the basis of the practical needs. Therefore, it provides the possibility to transform the original practical function to etiquette function. Finally, it is the ornamental function. In the evolution process of the prunus vase modeling, the times and society require it to carry out artistic processing in terms of capacity, proportion and size according to the change of functions. It would perfect the styling function and formal beauty of prunus vase. Then, it would realize the harmony of practical and aesthetic functions of prunus vase. With the changes of the times, the development of society and the improvement of technology, it would be suitable for people's lives and the use of wine storage devices with lower cost. The practical function of prunus vase has gradually withdrawn from the historical stage. Prunus vase modeling has tall, elegant, beautiful and artistic charm. Its aesthetic function occupies major position. In the end, the main function of ceramic prunus vase was changed from wine storage to display device. In the process of functional transformation, the shapes of prunus vase also have evolution. The aesthetic orientation leads to different degrees of changes in the mouth, neck, shoulder and shin of the prunus vase. It has led to the continuous evolution of prunus vase modeling.

\section{THE IMPROVEMENTS OF PROCESS MATERIALS AND TECHNOLOGY}

For the evolution of ceramic prunus vase shape, the craft, materials and technology are internal factors. According to Marxist materialist dialectics, we know that internal factors have decisive role. For example, the northern prunus vase generally is tall. The southern prunus vase is relatively short. It is determined by the nature of northern and southern porcelain. According to the research, the plasticity and verticality of northern kiln clay are generally better than that of the southern kiln clay. And the porcelain clay has superiority. The ancient traffic and information is not developed. The materials needed for the process production can't often be transported to each other between the North and the South rapidly. Generally, they would use the local materials. Therefore, the traditional prunus vase shape is limited to the raw material. For example, the northern craftsman can pull the porcelain into a larger prunus vase at one time. The southern raw material is relatively poor. The prunus vase in south is small. Even if there is some relatively large prunus vase in the south of China, it is made of segments. Of course, the northern prunus vase is also made of segments. And it only needs to take two or three paragraphs. For example, there are many examples of prunus vase combining multi sections with porcelain body in Jingdezhen Imperial Kiln Plant in Ming dynasty. And fivesection porcelain body is common. That is to say, the porcelain body is composed of five sections. In the Yongle period of Ming dynasty, it even appeared seven-section porcelain body. After that, we must carefully repair the porcelain body. And then, it may get exquisite and complete shape. Therefore, the shape of the prunus vase has close relationship with the process material. To a certain extent, the raw material determines the object shape. However, with the porcelain technology, furnace improvement and other technical conditions, this shortcoming can be overcome. For example, with the progress of the times, traffic conditions, porcelain craftsmanship and the improvement of kiln firing technology, the influence of differences in raw material on the shape of the prunus vase in the north and the south during the later development is getting smaller and smaller. Therefore, ceramic process materials and techniques have a direct impact on the style of ceramic prunus vase.

\section{THE PRINCIPLE AND REQUIREMENT OF ERGONOMIC ECONOMY}

First, the author would introduce the principle of motion economy of ergonomics. People; s operation has a direct impact on work efficiency. In order to improve work efficiency, people should reduce operational fatigue, seek the most reasonable action, and shorten the operation time. That is to say, people should pay attention to the economic principles of motion. At the beginning of the 20th century, Taylor and Gilbertres proposed this principle. Later, it was improved by Barnes and others in the United States. And they had made a conclusion that it was on the use of human actions, the layout and environmental conditions of workplaces, the design of tools and equipment, etc. [3]. In this paper, there are two main points. First, when moving the prunus vase and dumping the liquor in the bottle, the design of the traditional prunus vase conforms to the human physiological structure, instinct and habit. And it saves the operator's action as much as possible. And it takes advantage of the gravity, inertia, modeling structure of prunus vase to reduce the human action and effort. And it would keep the operator's gravity balanced. For example, through the shoulders and abdomen, the modeling of prunus vase is conducive to control the flow rate of the liquor. And in the same circumstances, we use the small effort to pour the liquid with rich shoulders. In addition, the shoulder and neck is full. And the gravity of prunus vase is close to the fulcrum. According to the principle of leverage, in the case of constant gravity, the smaller the torque is, the more effort is. The shape of prunus vase fully embodies the economic principles of ergonomics, which simplifies the action, shorten the action distance, reduce the number of actions and improve the efficiency. 2, the operator can maintain a reasonable and comfortable work attitude. When pouring the liquid in the prunus vase, the operator tilts slightly and squats his hands to hold the prunus vase. The posture not only helps control the flow rate of the liquid in the bottle, but also balances the center of gravity of the operator and poses natural and comfortable body posture. The shape design of prunus vase should be in line with the human body's physiological structure, size and the proportion. Its tall bottle increases the capacity. And the height does not exceed $50 \mathrm{~cm}$. We couldn't use too much strength to carry the bottle and pour the liquid. It is a reasonable amount for an adult. Therefore, the design of traditional ceramic prunus vase reflects the economic principles of ergonomics. And it would save labor and improve work efficiency. 


\section{FASHION OF THE TIMES AND ORIENTATION OF AEsTHETIC TASTE}

The change of times and the replacement of dynasties inevitably lead to the changes of social system, social customs, living habits and aesthetic taste. In a unique way, it should integrate the fashion of the times, social psychology and aesthetic taste into ceramics. And it embodies the style of all ages. And social factors have the opposite effect. It would affect the ceramic shape and decorative style. For example, the Tang dynasty was the heyday of China's feudal society. China vastly unified its territory. And it prospered the cultural exchange between China and foreign countries. Its social characteristics can be summed up as being unified, prosperous, and confident and open. Absolutely, its artistic style is characterized by its magnificence, gorgeous fullness and fun. And it can be described as "fullness" and "affection". In Song dynasty, artistic style is elegant, fresh and simple. From the perspective of aesthetics, the artistic style is very elegant. In Tang dynasty, art style can be summed up as "love". The characteristics in Song dynasty can be summarized as "truth". It is gorgeous in Tang dynasty. It is elegant in Song dynasty. It is magnificent in Tang dynasty. And it is rigorous and subtle in the Song dynasty. Therefore, the prunus vase in the Song dynasty presents tall, straight and elegant characteristics. If it admires the literature in Song Dynasty, it would admire the fierce in Yuan dynasty. Yuan rulers belong to the northern ethnic groups. They are tough and heroic. In order to expand the ruling territory, it has conducted a long-term campaign. The artistic style in the Yuan dynasty is rough, bold and vigorous [4]. The shape of ceramic prunus vase has also been reflected in the Yuan dynasty. The prunus vase is tall and thick. The art style of prunus vase in Ming dynasty has dignified and honest features. The porcelain technology in Qing dynasty has been developed. The materials can give full play to their performance. Therefore, the art style in Qing dynasty is delicacy and exquisite. During the Kangxi period, Qianlong period and Yongzheng period, the rulers love ceramic art, and even put forward specific opinions on the shape, glaze and pattern of ceramic ware. It promoted the prosperous development of the porcelain industry and created new varieties such as pastel and enamel. Therefore, the hobbies and interests of rulers in different ages will have impact on ceramic prunus vase. In short, social existence determines social consciousness, politics and economy. The philosophical and literary ideas have influence on the aesthetic awareness and creation trend of arts and crafts. However, aesthetic awareness and the fashion of the times also affect the style of specific arts and crafts. Apparently, it has influence on prunus vase modeling.

\section{CONCLUSION}

On the basis of inheriting the predecessors' modeling, the prunus vase modeling inherits the law of the same strain in the course of its development and evolution. Due to the passage of time, the change of times and the development of society, people's lifestyles and habits gradually change. The internal functional needs of prunus vase change. With the improvement of process materials and the use of advanced technology, it would provide means and the possibility for the modeling evolution of ceramic prunus vase. And then, the dominant aesthetic style in each dynasty, the different styles of art, the fashion of the times and the guidance of aesthetic taste would make the porcelain prunus vase inherit the features of the former dynasty. Meanwhile, it would draw lessons, develop and improve the advanced and excellent spiritual connotation and thinking mode. And we can join the spirit. Then, it could get continuous innovation and development. Therefore, the evolution of the modeling of the ceramic prunus vase is also the history of prunus vase. Through the study on the development of the modeling of the ancient Chinese prunus vase, it is a combination of simple skills and an objective reflection of the technological level. Also, it is self-reflection of the inner spirit and the characteristics of the times. It is a process to pursue beauty, create beauty and sublimate beauty.

\section{REFERENCES}

[1] Maslow. Human motivation theory [M]. Beijing: Huaxia Publishing House, 1987 edition, p. 162

[2] Xu Hengchun. Design aesthetics [M]. Beijing: Tsinghua University Press, July 2006 (1st edition), p. 50

[3] Yan Shengyuan, Xu Yuqing. Ergonomics and product design [M] Harbin: Harbin Engineering University Press, 2003, p. 48-49

[4] Tian Zibing. History of Chinese arts and crafts [M]. Shanghai: Oriental Press, 2006, p. 190-191 